\title{
The surface properties of cellulose and lignocellulosic materials assessed by inverse gas chromatography: a review
}

\author{
José A. F. Gamelas
}

Received: 27 June 2013/ Accepted: 18 September 2013/Published online: 1 October 2013

(C) Springer Science+Business Media Dordrecht 2013

\begin{abstract}
The physicochemical surface properties of cellulose and lignocellulosic materials are of major importance in the context of the production of composites, in papermaking, and textile area. These properties can be evaluated by using inverse gas chromatography (IGC), a particularly suitable technique for the characterization of the surface properties of fibrous materials and powders. At infinite dilution conditions of appropriate gas probes, IGC may provide important parameters including the dispersive component of the surface energy of the material under analysis, thermodynamic data on the adsorption of specific probes, and Lewis acid-base interaction parameters between the matrix and the filler of composite materials. This paper critically reviews the most relevant results available in the literature concerning the characterization of cellulose and lignocellulosic materials using IGC. Emphasis will be put into the cellulose and nanocellulose surface properties, changes in the surface properties of cellulose and lignocellulosic materials after chemical and physical modifications, and in the compatibility of cellulose-based materials with polymeric matrices. The surface properties of non-woody fibers will also be considered. Before discussing the results available
\end{abstract}

J. A. F. Gamelas ( $₫)$

Chemical Engineering Department, CIEPQPF, University of Coimbra, Pólo II, R. Sílvio Lima, 3030-790 Coimbra, Portugal

e-mail: jafgas@eq.uc.pt in the literature, the theoretical background and the main approaches used for the calculation of parameters accessed by IGC will be given. It is expected that this review can contribute to a better knowledge of the physicochemical surface properties of cellulosics.

Keywords Inverse gas chromatography .

Surface energy - Acid-base properties .

Cellulose $\cdot$ Polymers $\cdot$ Composites

\section{Introduction}

Inverse gas chromatography (IGC), firstly introduced in the sixties (Kiselev 1967; Smidsrod and Guillet 1969), has gained an increasing interest in the last two decades as a powerful tool to characterize the surface properties of solid materials: a search made on the Web of Science in 2013 provided ca. 2,300 articles reporting the application of IGC in diverse areas. Inverse gas chromatography is especially appropriate to study the thermodynamics of adsorption and the surface properties of organic and inorganic materials (Saint Flour and Papirer 1982; Belgacem et al. 1996; Belgacem and Gandini 1999; Belgacem 2000; Santos and Guthrie 2005). A wide range of materials can be analysed including polymers, fibers, fillers, pigments, building materials, coatings, supported catalysts, and microporous materials (Santos and Guthrie 2005). 
While in conventional gas chromatography the sample (mobile phase) is injected into a specific column (stationary phase) and the sample components are separated and quantified, in inverse gas chromatography the column is typically packed with the solid sample under investigation and a single gas or vapour (probe molecule) is injected into the column. This technique is based on the physical adsorption of wellknown probes by the sample's solid surface. From the retention time, $t_{\mathrm{r}}$, for a given probe, the free energy, enthalpy, and entropy of adsorption may be determined. The London dispersive component of the surface free energy (Dorris and Gray 1980; Schultz et al. 1987; Schultz and Lavielle 1989; Kamdem and Riedl 1992) and the acid-base surface properties (Saint Flour and Papirer 1982; Mukhopadhyay and Schreiber 1995), among other parameters, of the stationary phase can also be obtained by IGC. It should be noted that the dispersive and polar components of the surface energy can also be obtained from classical contact angle measurements. However, the surface roughness, the presence of pores, and surface energy gradients of some materials make the contact angle measurements less appropriate for surface energetics determinations (Riedl and Kamdem 1992). In fact, it has been reported that methods based on contact angle measurements (Wilhelmy and sessile drop methods, for instance) can lead to unrealistic results, particularly those concerning acid-base characteristics of the surface of the analysed material (Shen et al. 1999; Walinder and Gardner 2002). These limitations can be overcome using IGC, which is an accurate and versatile technique, enabling to obtain a wide range of surface physicochemical parameters of a solid material, not accessed by other techniques.

Cellulose and lignocellulosic materials belong to a class of materials that has been thoroughly studied using IGC, because of the importance of their physicochemical surface properties in the context of papermaking, textile area and, particularly, in the production of composites with polymeric matrices (Felix et al. 1993; Chtourou et al. 1997; Gauthier et al. 1998a; Matuana et al. 1998; Gulati and Sain 2006a; Gulati and Sain 2006b; Tze et al. 2006a, b; Dominkovics et al. 2007; Wang and Sain 2007; Gregorova et al. 2009; Rocha et al. 2009; Tonoli et al. 2010; Gamelas et al. 2012, 2013). The purpose of this article is to critically review and discuss the most relevant results available in the literature about the use of IGC to characterize the surface of cellulosics. This paper also aims to complement other reviews published before (Belgacem 2000; Shen 2009).

\section{Assessment of the surface parameters by IGC technique: theoretical background}

Determination of the dispersive component of the surface free energy

The retention of a gas or vapour probe molecule in the IGC column is quantified by the net retention volume, $V_{\mathrm{n}}$, which is the volume of inert carrier gas that is necessary to push the probe molecule through the chromatographic column containing the solid sample under analysis. At infinite dilution conditions, $V_{\mathrm{n}}$ depends on the sample-probe interactions and can be calculated from IGC data using Eq. (1). Here, $t_{\mathrm{r}}$ is the retention time of the injected probe through the column, $t_{0}$ is the retention time of the non-interacting probe (methane), $F$ is the flow rate of the inert carrier gas (measured with a digital flow meter), and $J$ is the James-Martin compression correction factor, determined by Eq. (2). Here, $P_{1}$ is equal to $P_{\mathrm{a}}$ (atmospheric pressure) plus the pressure drop in the column. It should be noted that the retention time may be calculated from the peak maximum (for chromatograms with symmetric shapes) or by using the Conder and Young method for less symmetric peaks (Conder and Young 1979; Kamdem and Riedl 1992).

$V_{\mathrm{n}}=\left(t_{\mathrm{r}}-t_{\mathrm{o}}\right) \cdot F . J$

$J=\frac{3}{2} \frac{\left[1-\left(P_{1} / P_{\mathrm{a}}\right)^{2}\right]}{\left[1-\left(P_{1} / P_{\mathrm{a}}\right)^{3}\right]}$

$V_{\mathrm{n}}$ is directly related to the adsorption equilibrium constant, $K_{\mathrm{s}}$, for the partitioning of the probe (adsorbate) between the mobile gas phase and the stationary phase (adsorbent), as shown in Eq. (3). Here, $A$ is the specific surface area of the adsorbent, $\Gamma$ is the surface concentration of the probe expressed in $\mathrm{mol} / \mathrm{m}^{2}$ and $c$ is its concentration on the gas phase (Dorris and Gray 1980; Gurnagul and Gray 1987; Mukhopadhyay and Schreiber 1995). 
$V_{\mathrm{n}}=A \cdot K_{\mathrm{s}}=A \cdot\left(\frac{\mathrm{d} \Gamma}{\mathrm{d} c}\right)_{c \rightarrow 0}$

Under infinite dilution conditions, Henry's Law is obeyed and thus:

$K_{\mathrm{s}}=\left(\frac{\mathrm{d} \Gamma}{\mathrm{d} c}\right)_{c \rightarrow 0}=\frac{\Gamma}{c}$

Assuming ideal gas behaviour, Eq. (5) is valid, where $P$ is the partial pressure of the probe, $R$ is the gas constant and $T$ is the column absolute temperature.

$c=\frac{P}{R T}$

Thus,

$K_{\mathrm{s}}=\Gamma \frac{R T}{P}$

$\Gamma$ is related to the surface pressure, $\pi$, through the Gibbs' equation (Eq. 7).

$\Gamma=\frac{1}{R T} p\left(\frac{\mathrm{d} \pi}{\mathrm{d} p}\right)$

At infinite dilution,

$\Gamma=\frac{p}{R T}\left(\frac{\pi}{p}\right)=\frac{\pi}{R T}$

And thus by combining Eqs. (6) and (8),

$K_{\mathrm{s}}=\frac{\pi}{P}$

The standard free energy of adsorption of the probe on the stationary phase (per mole), $\Delta G_{\mathrm{a}}^{0}$, from a reference gas phase to a reference adsorption phase defined by its equilibrium partial pressure, $P$, is expressed by Eq. (10).

$\Delta G_{\mathrm{a}}^{0}=R T \ln \frac{P}{P_{\mathrm{g}}^{\mathrm{s}}}$

In this equation, $P_{\mathrm{g}}^{\mathrm{s}}$ is the probe vapour pressure in the reference gas phase. Thus, by combining Eqs. (3), (9) and (10), Eq. (11) is obtained.

$\Delta G_{\mathrm{a}}^{0}=-R T \ln \frac{V_{\mathrm{n}} P_{\mathrm{g}}^{\mathrm{s}}}{\pi \cdot A}$

Assuming that the experiments take place at infinite dilution, the free energy of adsorption of the probe on the stationary phase surface, per mole, $\Delta G_{\mathrm{a}}$, can be determined from the retention volume, $V_{\mathrm{n}}$, according to Eq. (12). The constant $K$ is dependent on the chosen reference state (Dorris and Gray 1980; Mukhopadhyay and Schreiber 1995).

$\Delta G_{\mathrm{a}}=-R T \ln \left(V_{\mathrm{n}}\right)+K$

On the other hand, the free energy of adsorption can be related to the work of adhesion, $W_{\mathrm{a}}$, according to Eq. (13), where $N$ is the Avogadro number and $a$ is the molecular surface area of the probe (Mukhopadhyay and Schreiber 1995).

$-\Delta G_{\mathrm{a}}=N \cdot a \cdot W_{\mathrm{a}}$

If only dispersive interactions occur, the work of adhesion can be given by Eq. (14) (Fowkes 1964), where $\gamma_{\mathrm{s}}^{\mathrm{d}}$ and $\gamma_{1}^{\mathrm{d}}$ are the dispersive components of the surface free energy of the interacting solid and probe, respectively.

$W_{\mathrm{a}}=2 \sqrt{\gamma_{\mathrm{s}}^{\mathrm{d}} \cdot \gamma_{1}^{\mathrm{d}}}$

Thus, based on Eqs. (12), (13) and (14), the net retention volume, $V_{\mathrm{n}}$, can be related to the dispersive components of the surface energy, $\gamma_{\mathrm{s}}^{\mathrm{d}}$ and $\gamma_{1}^{\mathrm{d}}$, by Eq. (15).

$R T \ln \left(V_{\mathrm{n}}\right)=\sqrt{\gamma_{\mathrm{s}}^{\mathrm{d}}} 2 N \cdot a \sqrt{\gamma_{1}^{\mathrm{d}}}+K$

According to Eq. (15), it is possible to estimate the dispersive component of the surface energy of a sample from the slope of the linear fit of $R T \ln \left(V_{\mathrm{n}}\right)$ as a function of $2 N \cdot a\left(\gamma_{1}^{\mathrm{d}}\right)^{0.5}$, using the IGC data obtained with the apolar probes (Schultz et al. 1987; Schultz and Lavielle 1989). It should be noted that the dispersive component of the surface energy represents the potential of materials to undergo London dispersion interactions. The main weakness of the Schultz and Lavielle approach is the uncertainty of the molecular surface area values of the adsorbed species. Molecular areas of non-spherical adsorbed molecules may change depending on the orientation of the molecules on the material surface. In addition, the temperature influence on the molecular areas is not usually taken into account. Several corrections to the molecular areas values have been proposed to solve this problem (Mukhopadhyay and Schreiber 1995; Santos and Guthrie 2005).

A related approach to calculate the dispersive component of the surface energy was proposed by Dorris and Gray (1980) (Eq. 16). In this equation, $R T \ln \left[V_{\mathrm{n}}\left(\mathrm{C}_{\mathrm{n}+1} \mathrm{H}_{2 \mathrm{n}+4}\right) / V_{\mathrm{n}}\left(\mathrm{C}_{\mathrm{n}} \mathrm{H}_{2 \mathrm{n}+2}\right)\right]$ corresponds to the difference in the free energy of adsorption due to the 


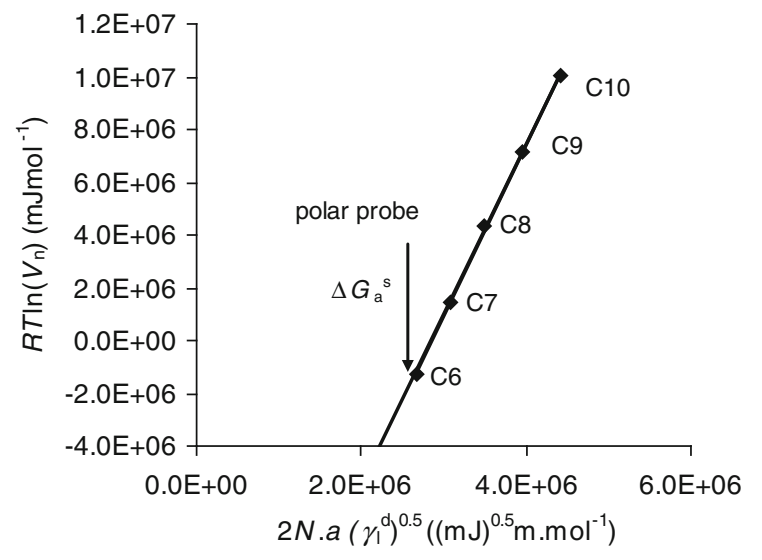

Fig. 1 Determination of $\Delta G_{\mathrm{a}}^{\mathrm{s}}$ of a polar probe

introduction of an additional $-\mathrm{CH}_{2}-$ group into the carbon chain of a $n$-alkane probe. $a_{\mathrm{CH} 2}$ is the molecular area of the $-\mathrm{CH}_{2}-$ group, which is usually taken as $0.06 \mathrm{~nm}^{2}$. This may not be the most accurate value and corrections for the Dorris and Gray approach have been proposed by Goss (1997). $\gamma_{\mathrm{CH}_{2}}$ is the surface energy of a solid entirely composed of methylene groups, known to be $35.6 \mathrm{~mJ} \mathrm{~m}^{-2}$ at $20^{\circ} \mathrm{C}$ (Dorris and Gray 1980; Mukhopadhyay and Schreiber 1995). Typically, the $\gamma_{s}^{\mathrm{d}}$ values obtained by the Dorris and Gray approach do not differ much from those obtained using the Schultz and Lavielle approach.

$$
\gamma_{\mathrm{s}}^{\mathrm{d}}=\frac{\left[R T \ln \frac{V_{\mathrm{n}}^{\left(\mathrm{C}_{\mathrm{n}+1} \mathrm{H}_{2 \mathrm{n}+4}\right)}}{V_{\mathrm{n}}^{\left(\mathrm{C}_{\mathrm{n}} \mathrm{H}_{2 \mathrm{n}+2}\right)}}\right]^{2}}{4 N^{2}\left(a_{\mathrm{CH}_{2}}\right)^{2} \gamma_{\mathrm{CH}_{2}}}
$$

The Schultz/Lavielle and the Dorris/Gray approaches have been by far the methods most employed to calculate the dispersive component of the surface free energy of cellulose and lignocellulosic materials. However, other methods are available to calculate $\gamma_{\mathrm{s}}^{\mathrm{d}}$ (Santos and Guthrie 2005). The Donnet approach (Donnet et al. 1991, 1992) based on the use of a polarizability index of the probe has also been applied to analyse lignocellulosics. Another interesting approach is that of Brendlé and Papirer (1997a, b) suggesting the use of a topological index that accounts for the geometry of the probe.

Specific parameters related to acid-base properties

If a Lewis acid-Lewis base interaction occurs, as is the case with polar probes, there will be a corresponding specific component contribution, $\Delta G_{\mathrm{a}}^{\mathrm{s}}$, in addition to the dispersive component, to the overall free energy of adsorption, $\Delta G_{\mathrm{a}}$ (Mukhopadhyay and Schreiber 1995). The overall free energy of adsorption, $\Delta G_{\mathrm{a}}$, is related to the net retention volume by Eq. (12). Therefore, the free energy of adsorption that is caused by specific interactions, $\Delta G_{\mathrm{a}}^{\mathrm{s}}$, can be estimated by calculating the difference between the values of $R T \ln \left(V_{\mathrm{n}}\right)$ obtained for the polar probe and the corresponding estimation for the apolar probe. The graphical method is represented in Fig. 1.

If the experiments take place at different temperatures, it is possible to calculate the specific component of the enthalpy of adsorption, $\Delta H_{\mathrm{a}}^{\mathrm{s}}$, and the specific component of the entropy of adsorption, $\Delta S_{\mathrm{a}}^{\mathrm{s}}$, by plotting $\Delta G_{\mathrm{a}}^{\mathrm{s}} / T$ versus $1 / T$ (Eq. 17). On the other hand, the specific component of the enthalpy of adsorption, $\Delta H_{\mathrm{a}}^{\mathrm{s}}$, can be related to the electron acceptor and electron donor parameters of the sample's solid surface, $K_{\mathrm{a}}$ and $K_{\mathrm{b}}$, respectively, by Eq. (18) (Schultz et al. 1987; Chtourou et al. 1995; Mukhopadhyay and Schreiber 1995). $K_{\mathrm{a}}$ is the Lewis acidity constant and $K_{\mathrm{b}}$ is the Lewis basicity constant. $D N$ and $A N^{*}$ are the Gutmann's electron donor and electron acceptor numbers, respectively, of the acid-base probe (Gutmann 1978; Riddle and Fowkes 1990). The donor number $(D N)$ parameter is defined as the negative enthalpy value for the reaction of the liquid under test with the acceptor $\mathrm{SbCl}_{5}$. The acceptor number $(A N)$ parameter is defined as the relative ${ }^{31} \mathrm{P}$ NMR chemical shift of triethylphosphine oxide $\left(\mathrm{Et}_{3} \mathrm{PO}\right)$, when this donor substance is dissolved in the liquid under evaluation (when the liquid is hexane, $A N$ is set to zero) (Gutmann 1978). $A N^{*}$ is obtained from $A N$ after correcting from the London dispersion forces contribution to the chemical shift, in order to obtain the true acid-base contribution (Riddle and Fowkes 1990). The physical properties of a few apolar and polar probes commonly used in IGC, including the Lewis donor and acceptor numbers, are listed in Table 1. According to Eq. (18), $K_{\mathrm{a}}$ and $K_{\mathrm{b}}$ can be graphically determined by plotting $-\Delta H_{\mathrm{a}}^{\mathrm{s}} / A N^{*}$ versus $D N / A N^{*}: K_{\mathrm{a}}$ is obtained as the slope of the linear fit, whereas $K_{\mathrm{b}}$ is the origin of such plot.

$$
\begin{aligned}
& \frac{\Delta G_{\mathrm{a}}^{\mathrm{s}}}{T}=\frac{\Delta H_{\mathrm{a}}^{\mathrm{s}}}{T}-\Delta S_{\mathrm{a}}^{\mathrm{s}} \\
& -\Delta H_{\mathrm{a}}^{\mathrm{s}}=K_{\mathrm{a}} D N+K_{\mathrm{b}} A N^{*}
\end{aligned}
$$


Table 1 Properties of common probes used in the calculation of surface parameters by IGC

\begin{tabular}{llllll}
\hline Probe & Type & $a\left(\AA^{2}\right)$ & $\gamma_{1}^{\mathrm{d}}\left(\mathrm{mJ} \mathrm{m}^{-2}\right)$ & $D N\left(\mathrm{KJ} \mathrm{mol}^{-1}\right)$ & $A N^{*}\left(\mathrm{KJ} \mathrm{mol}^{-1}\right)$ \\
\hline$n$-Hexane & Apolar & 51.5 & 18.4 & & \\
$n$-Heptane & Apolar & 57.0 & 20.3 & & \\
$n$-Octane & Apolar & 63.0 & 21.3 & & \\
$n$-Nonane & Apolar & 69.0 & 22.7 & & \\
$n$-Decane & Apolar & 75.0 & 23.4 & 0 & 22.7 \\
Trichloromethane & Acid & 44.0 & 25.0 & 0 & 16.4 \\
Dichloromethane & Acid & 31.5 & 27.6 & 84.4 & 2.1 \\
Tetrahydrofurane & Base & 45.0 & 22.5 & 71.8 & 6.3 \\
Ethyl acetate & Amphoteric & 48.0 & 19.6 & 71.4 & 10.5 \\
Acetone & Amphoteric & 42.5 & 16.5 &
\end{tabular}

Riddle and Fowkes (1990), Kamdem et al. (1993), Santos and Guthrie (2005)

In Eq. (18), the parameter $\Delta H_{\mathrm{a}}^{\mathrm{s}}$ obtained from the plot of $\Delta G_{\mathrm{a}}^{\mathrm{s}} / T$ versus $1 / T$ at several temperatures may be substituted by $\Delta G_{\mathrm{a}}^{\mathrm{s}}$, obtained at a single temperature $\left(-\Delta G_{\mathrm{a}}^{\mathrm{s}}=K_{\mathrm{a}} D N+K_{\mathrm{b}} A N^{*}\right)$ (Saint Flour and Papirer 1983; Chehimi et al. 1999). The absolute values of the Lewis acidity and basicity constants obtained by the latter process are then quite different from those obtained by using $-\Delta H_{\mathrm{a}}^{\mathrm{s}}$ in Eq. (18). Thus, when considering Lewis acid-base constants from different literature reports it must be checked which of the aforementioned calculation methods has been used for their determination.

On the other hand, the straight comparison of the $K_{\mathrm{a}}$ values with the $K_{\mathrm{b}}$ values in terms of the prevalence of the acidic or basic properties should be made with due caution since it may not be possible to compare the scales of acidity $\left(K_{\mathrm{a}}\right)$ and basicity $\left(K_{\mathrm{b}}\right)($ Chehimi et al. 1999; Walinder and Gardner 2002). Whereas the donor number $(D N)$ scale uses $\mathrm{SbCl}_{5}$ as reference which is a soft acid, the acceptor number $\left(A N^{*}\right)$ scale is based on the ${ }^{31} \mathrm{P}$ NMR chemical shift of $\mathrm{Et}_{3} \mathrm{PO}$, which is a hard base. $D N$ is a scale of softness whereas $A N^{*}$ is a scale of hardness.

Lewis acid-base interaction numbers from IGC

The determination of interaction parameters $\left(I_{\mathrm{sp}}\right)$ related to surfaces adhesion may be used as a tool to predict the compatibility of two different materials to produce composite structures. The values of these parameters may be correlated with the physical/ mechanical properties of the ensuing materials. These interaction parameters may be calculated by different ways as follows from Eqs. (19) and (20) (Chtourou et al. 1997; Matuana et al. 1998).

$$
\begin{aligned}
I_{\mathrm{sp}}= & K_{\mathrm{a}}^{\mathrm{f}} K_{\mathrm{b}}^{\mathrm{m}}+K_{\mathrm{a}}^{\mathrm{m}} K_{\mathrm{b}}^{\mathrm{f}} \\
I_{\mathrm{sp}}= & 2\left(P^{\mathrm{m}}\right)^{2}\left(K_{\mathrm{a}}^{\mathrm{m}} K_{\mathrm{b}}^{\mathrm{m}}\right)+2\left(P^{\mathrm{f}}\right)^{2}\left(K_{\mathrm{a}}^{\mathrm{f}} K_{\mathrm{b}}^{\mathrm{f}}\right) \\
& +\frac{1}{2}\left(P^{\mathrm{m}}\right)\left(P^{\mathrm{f}}\right)\left(K_{\mathrm{a}}^{\mathrm{m}} K_{\mathrm{b}}^{\mathrm{f}}+K_{\mathrm{a}}^{\mathrm{f}} K_{\mathrm{b}}^{\mathrm{m}}\right)
\end{aligned}
$$

In these equations, the superscripts $m$ and $f$ represent the matrix and the filler, respectively, of the composite. Equation (20) takes also into account the proportion of the matrix $\left(P^{\mathrm{m}}\right)$ and the filler $\left(P^{\mathrm{f}}\right)$ in the composite and the different possible interfaces, namely matrix-matrix, filler-filler, and matrix-filler. Stronger interactions between the matrix and the filler are expected for higher interaction numbers.

\section{The use of IGC to analyse the surface properties of cellulose and lignocellulosic materials}

Cellulose analyses by IGC

The surface properties of cellulose have been thoroughly studied. The dispersive component of the surface energy and the acid-base properties were assessed by IGC (Dorris and Gray 1980; Lee and Luner 1989, 1993; Felix and Gatenholm 1993a, b; Felix et al. 1993, 1994; Garnier and Glasser 1994, 1996; Jacob and Berg 1994; Belgacem et al. 1995, 1996; Tshabalala 1997; Botaro and Gandini 1998; Trejo-O'Reilly et al. 1998; Papirer et al. 2000; Borges et al. 2001; Peng and Zou 2007; Steele et al. 2008; 
Peterlin et al. 2010). Regarding the dispersive component of the surface energy $\left(\gamma_{\mathrm{s}}^{\mathrm{d}}\right)$ the majority of the reported values fall within the range of 40-50 $\mathrm{mJ} \mathrm{m}^{-2}$, although other values have been published. For instance, at $40{ }^{\circ} \mathrm{C}$, cotton cellulose was reported to have a $\gamma_{\mathrm{s}}^{\mathrm{d}}$ value of $50 \mathrm{~mJ} \mathrm{~m}^{-2}$ (Dorris and Gray 1980), purified hardwood $\alpha$-cellulose showed a $\gamma_{\mathrm{s}}^{\mathrm{d}}$ value of $47.4 \mathrm{~mJ} \mathrm{~m}^{-2}$ (Belgacem et al. 1995, 1996), and cellulose powder presented a $\gamma_{\mathrm{s}}^{\mathrm{d}}$ of $48 \mathrm{~mJ} \mathrm{~m}^{-2}$ (Tshabalala 1997). Recently, the dispersive component of the surface energy of microcrystalline celluloses was assessed by IGC at 0 and $44 \%$ relative humidity (RH) (Steele et al. 2008). Values were in the range of $41-46 \mathrm{~mJ} \mathrm{~m}^{-2}$ for the determinations carried out at $44 \% \mathrm{RH}$. Interestingly, the results obtained under these conditions were in reasonable agreement with those obtained by capillary intrusion method. Somewhat larger values of $\gamma_{\mathrm{s}}^{\mathrm{d}}$ $\left(5-10 \mathrm{~mJ} \mathrm{~m}^{-2}\right.$ higher) were obtained at $0 \% \mathrm{RH}$ suggesting the inhibition of high-energy adsorption sites by water molecules at $44 \% \mathrm{RH}$.

Although cellulose has a well-defined molecular structure, the fact that this material is difficult to obtain in pure chemical form (i.e., without surface contaminants) should greatly account for some variety of the reported IGC results. It has been proposed that, besides the chemical composition of the cellulose surface, other factors such as crystallinity, diffusion of probes into the bulk volume and surface morphology also play an important role in the interaction between the probes and the cellulose surfaces and thus influence the IGC data (Chtourou et al. 1995; Papirer et al. 2000). Concerning crystallinity, it has been reported that microcrystalline cellulose shows a significantly higher $\gamma_{\mathrm{s}}^{\mathrm{d}}$ value at $50{ }^{\circ} \mathrm{C}\left(40.9 \mathrm{~mJ} \mathrm{~m}^{-2}\right)$ than that calculated by an empirical method for "amorphous" cellulose (28 $\mathrm{mJ} \mathrm{m}^{-2}$ ) (Belgacem et al. 1996; Papirer et al. 2000). Overall, for the analysis of the effects of chemical and physical treatments on the cellulose surface (discussed below) care must be taken when considering a single value for the dispersive component of the surface energy of cellulose.

The adhesion and surface properties of nanocellulose are a very important issue due to the increasing interest in this nanomaterial (Gardner et al. 2008). The surface properties of nanofibers obtained by enzymatic treatments were analysed by IGC (Siddiqui et al. 2011). The authors reported $\gamma_{s}^{d}$ values in the range of $37-45 \mathrm{~mJ} \mathrm{~m}^{-2}$ (at $40{ }^{\circ} \mathrm{C}$ ), which are not very different from those expected for cellulose fibers. A $\gamma_{\mathrm{s}}^{\mathrm{d}}$ value of $42 \mathrm{~mJ} \mathrm{~m}^{-2}$, comprised in the same range, was also reported for hemp cellulose nanofibers (Wang and Sain 2007). Bacterial cellulose was found to have a relatively high $\gamma_{\mathrm{s}}^{\mathrm{d}}$ value, i.e., $61 \mathrm{~mJ} \mathrm{~m}^{-2}$ in comparison to other cellulose types (Pommet et al. 2008). The authors proposed that this could be due to its high degree of crystallinity compared to plant derived cellulose.

Regarding the acid-base properties of cellulose, it has been found by IGC that the cellulose surface has an amphoteric behaviour, i.e., both acidic (electron acceptor) and basic (electron donor) properties (Lee and Luner 1989; Felix et al. 1993; Jacob and Berg 1994; Belgacem et al. 1995; Tshabalala 1997; TrejoO'Reilly et al. 1998; Papirer et al. 2000; Borges et al. 2001). In addition, it is predominantly acidic rather than basic. These conclusions have been drawn from the determination of $-\Delta G_{\mathrm{a}}^{\mathrm{s}}\left(\right.$ or $W_{\mathrm{a}}^{\mathrm{s}}$ ) with several polar probes, being the greatest values obtained with amphoteric probes, such as acetone. Moreover, when comparing the $-\Delta G_{\mathrm{a}}^{\mathrm{s}}$ values obtained with representative basic and acidic probes (e.g., tetrahydrofurane and trichloromethane, respectively), these are higher with the basic probes, indicating a more acidic than basic character of the cellulose surfaces. Typically, the $K_{\mathrm{a}}$ values are also higher than the $K_{\mathrm{b}}$ ones (this may confirm a prevalence of the acidic character, although, as mentioned above the scales of these constants are not directly compared).

A $K_{\mathrm{a}}$ value of 0.11 and a $K_{\mathrm{b}}$ of 0.41 have been reported for bacterial cellulose (Pommet et al. 2008). This result seems to indicate that in comparison to conventional plant cellulose, the surface of bacterial cellulose has enhanced basic properties. The reason for this is not clear but it can be speculated to be a consequence of the different morphology and surface area of the bacterial cellulose fibers. Comparable results have been obtained for hemp cellulose nanofibers $\left(K_{\mathrm{a}}=0.19\right.$ and $K_{\mathrm{b}}=0.31$, calculated using Eq. 18) (Wang and Sain 2007).

Functionalization of cellulose and lignocellulosics: changes in the surface properties measured by IGC

A great number of studies concerned the functionalization of cellulose and lignocellulosics and its effect on the surface properties of these materials. The surface modification of microcrystalline cellulose 
(Avicel) with reagents containing anhydride and isocyanate reactive moieties (including alkenyl succinic anhydride, styrene-maleic anhydride copolymer, copolymers involving isocyanate and styrene or $\alpha$ methylstyrene, monomeric isocyanates) has been carried out (Botaro and Gandini 1998; Trejo-O'Reilly et al. 1998; Belgacem 2000). The most important finding obtained by IGC analyses was the great enhancement of the Lewis basic character of the cellulose surface after these surface treatments. This was proposed to result from the formation of urethane or ester moieties derived from the coupling reactions (Bach et al. 2005). The substitution of some of the hydroxyl groups in cellulose beads (regenerated cellulose) by trifluoroethoxyacetate functionalities also greatly increased the basic character of the material surface and decreased the acidic one (Garnier and Glasser 1996).

The esterification of cellulose (powder) by acyl chlorides, namely valeryl $\left(\mathrm{C}_{5}\right)$ and palmitoyl $\left(\mathrm{C}_{16}\right)$ chlorides was performed aiming to obtain products with a higher compatibility with polypropylene than the unmodified fibers (Gauthier et al. 1998b). The dispersive component of the surface energy decreased greatly after the esterification reactions, achieving a value close to that of polypropylene. Moreover, the $\gamma_{s}^{\mathrm{d}}$ values of the cellulose palmitate products were lower than those of the cellulose valerates and, for the latter, when the degree of substitution (DS) increased, the $\gamma_{\mathrm{s}}^{\mathrm{d}}$ value decreased (Table 2). The Lewis basic character as measured by the $-\Delta G_{\mathrm{a}}^{\mathrm{s}}$ (trichloromethane) increased after esterification and the Lewis acidic character as measured by the $-\Delta G_{\mathrm{a}}^{\mathrm{s}}$ (diethyl ether) decreased, as expected for the substitution of hydroxyl groups by ester bonds (Gauthier et al. 1998b). Similar results have been obtained regarding the trends of the $\gamma_{\mathrm{s}}^{\mathrm{d}}$ and the Lewis acid properties when using several $\mathrm{C}_{11}$ and $\mathrm{C}_{18}$ fatty acids for the cellulose esterification (Jandura et al. 2002). However, in this case, the Lewis basic properties of the cellulose surface, as measured by the $K_{\mathrm{b}}$ constant, did not show any significant change with the chemical modification. No explanation has been offered for this fact. The sizing of filter paper (mostly $\alpha$-cellulose) with alkenyl ketene dimer, which is thought to introduce ester functionalities in the cellulose chain, also reduced the $\gamma_{\mathrm{s}}^{\mathrm{d}}$ values, increased the Lewis basicity $\left(-\Delta G_{\mathrm{a}}^{\mathrm{s}}\right.$ of trichloromethane) and decreased the Lewis acidity $\left(-\Delta G_{\mathrm{a}}^{\mathrm{s}}\right.$ of diethyl ether) (Shen et al. 2000). Different results had been obtained previously by Lee and Luner (1989).

Cellulose and lignocellulosic fibers were treated with maleated polypropylene, dichlorodiethylsilane (or dichlorodimethylsilane), $\gamma$-aminopropyltriethoxysilane, and phthalic anhydride, and analysed by IGC (Felix and Gatenholm 1993b; Felix et al. 1993; Kazayawoko et al. 1997, 1999; Coupas et al. 1998; Matuana et al. 1998, 1999). Significant changes of the fiber's acid-base properties have been found, as summarized in Table 3 for newsprint fibers. The basic character of the pulp fibers was enhanced by the treatments with maleated polypropylene, probably due to the formation of ester bonds between the cellulose hydroxyl groups and the anhydride groups from maleated polypropylene (Coupas et al. 1998; Matuana et al. 1998). Dichlorodiethylsilane produced a strong acidic surface attributed to the highly electronegative nature of the chlorine atoms of dichlorodiethylsilane (Felix et al. 1993; Matuana et al. 1998). For the fibers treated with $\gamma$-aminopropyltriethoxysilane, the basic characteristic of the fiber surface increased due to the presence of attached amino groups (Felix et al. 1993; Matuana et al. 1998).

When chemithermomechanical pulp fibers were modified by phenol-formaldehyde resins, the $\gamma_{s}^{\mathrm{d}}$ value increased from $27.5 \mathrm{~mJ} \mathrm{~m}^{-2}$ for the untreated fibers to $42.5 \mathrm{~mJ} \mathrm{~m}^{-2}$ for the fibers treated with $20 \mathrm{wt} \%$ highmolecular weight phenol-formaldehyde resin (PFR). For fibers modified with different types and amounts of PFR and the unmodified fibers an inverse relationship between $\gamma_{\mathrm{s}}^{\mathrm{d}}$ obtained by IGC and the O/C atomic ratio estimated by $\mathrm{X}$-ray photoelectron spectroscopy (XPS; this surface sensitive technique gives information of the chemical composition of the surface up to approximately $10 \mathrm{~nm}$ depth) was found, that is, the $\gamma_{\mathrm{s}}^{\mathrm{d}}$ value increased when the $\mathrm{O} / \mathrm{C}$ atomic ratio decreased (Kamdem and Riedl 1991). On the other hand, the modification of bleached softwood kraft fibers via adsorption of organo-nanoclay afforded a decrease of the dispersive component of the surface energy from 44 to $30 \mathrm{~mJ} \mathrm{~m}^{-2}$ (at $60{ }^{\circ} \mathrm{C}$ ) (Chen and Yan 2012). The $\gamma_{\mathrm{s}}^{\mathrm{d}}$ also increased after subjecting aqueous suspensions of thermomechanical pulp fibers to ultrasonic radiation (Gadhe et al. 2006).

The surface properties of cellulose acetate butyrate and cellulose ethers were also assessed by IGC (Sasa et al. 2006; Rani et al. 2011). Cellulose acetate butyrate was found to have a $\gamma_{\mathrm{s}}^{\mathrm{d}}$ value of $18 \mathrm{~mJ} \mathrm{~m}^{-2}$ at 
Table 2 Esterification of cellulose powder: surface parameters assessed by IGC

\begin{tabular}{lllll}
\hline Material & $\begin{array}{l}\gamma_{\mathrm{s}}^{\mathrm{d}} \\
\left(\mathrm{mJ} \mathrm{m}^{-2}\right)\end{array}$ & $\begin{array}{l}-\Delta G_{\mathrm{a}}^{\mathrm{s}}(\mathrm{TCM}) \\
\left(\mathrm{KJ} \mathrm{mol}^{-1}\right)\end{array}$ & $\begin{array}{l}-\Delta G_{\mathrm{a}}^{\mathrm{s}}(\text { ether }) \\
\left(\mathrm{KJ} \mathrm{mol}^{-1}\right)\end{array}$ & $\begin{array}{l}\Delta G_{\mathrm{a}}^{\mathrm{s}}(\mathrm{TCM}) / \\
\Delta G_{\mathrm{a}}^{\mathrm{s}}(\text { ether })\end{array}$ \\
\hline Cellulose & 43.7 & 1.40 & 6.39 & 0.22 \\
Cellulose valerate, $\mathrm{C}_{5}(\mathrm{DS}=0.15)$ & 36.2 & 1.62 & 3.84 & 0.42 \\
Cellulose valerate, $\mathrm{C}_{5}(\mathrm{DS}=0.41)$ & 32.1 & 4.00 & 3.18 & 1.26 \\
Cellulose palmitate, $\mathrm{C}_{16}(\mathrm{DS}=0.15)$ & 28.5 & 3.77 & 3.12 & 1.21 \\
Cellulose palmitate, $\mathrm{C}_{16}(\mathrm{DS}=0.45)$ & 28.4 & 3.20 & 2.03 & 1.58 \\
\hline
\end{tabular}

Gauthier et al. (1998b); all determinations made at $70{ }^{\circ} \mathrm{C}$; $\mathrm{TCM}=$ trichloromethane

Table 3 Lewis acid-base characteristics of newsprint fibers after chemical modification

\begin{tabular}{lll}
\hline Fibers & $K_{\mathrm{a}}$ & $K_{\mathrm{b}}$ \\
\hline Untreated newsprint fibers & 0.65 & 0.16 \\
Maleated polypropylene-treated fibers & 0.68 & 0.35 \\
Dichlorodiethylsilane-treated fibers & 1.41 & 0.05 \\
Aminosilane-treated fibers & 0.57 & 0.96 \\
Phthalic anhydride-treated fibers & 0.87 & 0.20 \\
\hline
\end{tabular}

Matuana et al. (1998); $K_{\mathrm{a}}$ and $K_{\mathrm{b}}$ values have been obtained from the $\Delta H_{\mathrm{a}}^{\mathrm{s}}$ of several probes

$50{ }^{\circ} \mathrm{C}$. For this material, a higher interaction was observed with amphoteric probes than with acidic or basic ones, as measured by the $-\Delta H_{\mathrm{a}}^{\mathrm{s}}$ parameter with different probes $\left(50-120{ }^{\circ} \mathrm{C}\right.$ temperature range). In addition, $-\Delta H_{\mathrm{a}}^{\mathrm{s}}$ (trichloromethane or dichloromethane) $>-\Delta H_{\mathrm{a}}^{\mathrm{s}}$ (tetrahydrofurane) indicating a prevalence of basic character. The $K_{\mathrm{a}}$ and $K_{\mathrm{b}}$ values were 0.126 and 1.109 confirming that the surface of the cellulose derivative is predominantly basic (Rani et al. 2011). This is in accordance with the expectations from the structure of the compound which presents Lewis basic oxygen atoms in the ester moieties. The specific interactions of cellulose ethers, namely hydroxyethylcellulose (HEC), hydroxypropylcellulose (HPC) and hydroxypropylmethylcellulose (HPMC) with several polar probes were evaluated using a similar approach (based on the calculation of $-\Delta H_{\mathrm{a}}^{\mathrm{s}}$ ) and the authors found that the interactions increased in the order HPC $<$ HPMC $<$ HEC (Sasa et al. 2006). These results correlated well with water adsorption on these cellulose derivatives and with their swelling ability. Moreover, the release rate of water-soluble drugs, pentoxifylline and vancomycin, from cellulose ether matrices followed the same order predicted from the ethers polarity.
Effects of organic solvent extraction, recycling, hot water extraction, beating, and bleaching on the surface of cellulose-based materials

Several researchers have studied the effect of organic solvent extraction on the surface properties of cellulose and lignocellulosic materials. For instance, Belgacem et al. $(1995,1996)$ reported that the acetone extraction of $\alpha$-cellulose fibers increased the dispersive component of the surface energy from 31.9 to $47.4 \mathrm{~mJ} \mathrm{~m}^{-2}$ (at $40{ }^{\circ} \mathrm{C}$ ). This was attributed mainly to the removal of low molecular weight components at the fiber surface, such as fatty acids, which possess lower $\gamma_{\mathrm{s}}^{\mathrm{d}}$ values than cellulose. Similar results have been obtained after extraction of Avicel cellulose fibers with acetone or dichloromethane (Borges et al. 2001).

The influence of organic solvent extraction and recycling on the surface properties of bleached kraft pulps, namely on the dispersive component of the surface energy and on the surface acid-base character was reported (Shen et al. 1998a; Tze and Gardner 2001). It was confirmed the dominant acidic character of a bleached eucalypt kraft pulp, taken as reference pulp (that is, not extracted and not recycled) since higher work of adhesion was obtained with basic probe (Table 4). However, for fines separated from the reference pulp, the basic character was clearly more pronounced than the acidic one. The extraction with ethanol-benzene led to an increase of the $\gamma_{\mathrm{s}}^{\mathrm{d}}$ and the works of adhesion with polar probes (Table 4), mainly due to the extractives removal from the pulp surface and higher exposure of the cellulose macromolecules to the IGC probes. Pulp recycling afforded less polar pulps' surfaces (Table 4). Subsequent extraction of recycled fibers had effects similar to those obtained for the extraction of the reference kraft pulp (Shen et al. 
Table 4 Effects of the organic solvent extraction and recycling on the surface properties of eucalypt kraft pulps, assessed by IGC

Shen et al. (1998a, b), Shen and Parker (1999); measurements made at 40 or $37^{\circ} \mathrm{C}$

\begin{tabular}{lllc}
\hline Eucalypt kraft pulps & $\begin{array}{l}\gamma_{\mathrm{s}}^{\mathrm{d}} \\
\left.(\mathrm{mJ} \mathrm{m})^{-2}\right)\end{array}$ & $\begin{array}{l}W_{\mathrm{a}}^{\mathrm{s}}(\text { trichloromethane }) \\
\left(\mathrm{mJ} \mathrm{m}^{-2}\right)\end{array}$ & $\begin{array}{l}W_{\mathrm{a}}^{\mathrm{s}}(\text { diethyl ether }) \\
\left(\mathrm{mJ} \mathrm{m}^{-2}\right)\end{array}$ \\
\hline A. Bleached pulp (reference) & 38.4 & 2.4 & 11.2 \\
Fines separated from $A$ & 34.7 & 6.9 & 0.3 \\
A extracted with ethanol/benzene & 42.8 & 11.3 & 23.4 \\
B. Reference recycled & 33.7 & 1.6 & 3.7 \\
B after extraction with ethanol/toluene & 43.3 & 2.6 & 19.9 \\
C. Unbleached E. Globulus pulp & 41.8 & 4.4 & 8.9 \\
C extracted with methanol & 50.7 & 9.9 & 24.6 \\
\hline
\end{tabular}

1998a). Still regarding recycling, Tze and Gardner (2001) found by IGC that the surface of recycled kraft fibers and virgin fibers had similar electron donating/ electron accepting capacities. The effect of recycling on the fibers surface properties certainly deserves additional studies.

When (unbleached) eucalypt pulps obtained by kraft cooking, neutral sulphite semichemical (NSSC) and cold soda processes were extracted with methanol, an increase of the $\gamma_{\mathrm{s}}^{\mathrm{d}}$ value was found, from 36.2-41.8 to $50.7-62.2 \mathrm{~mJ} \mathrm{~m}^{-2}$ (Table 4, kraft pulp) (Shen and Parker 1999). Similar trend was also observed for spruce and white pine wood particles after extraction (Liu et al. 1998; Walinder and Gardner 2000). Concerning the acid-base properties, the magnitude of the works of adhesion was found to increase with the extraction for the several pulp types studied, being the acidic character more enhanced than the basic one (Table 4, kraft pulp). The extractives removal on the pulp surface unblocked some high-energy sites, mainly from cellulose and hemicelluloses chains, which possess more acidic than basic character, setting free these sites to interact with the polar probes (Shen and Parker 1999). When wood was extracted with organic solvents the acid-base characteristics were also enhanced (Liu et al. 1998). Moreover, a correlation between the $K_{\mathrm{a}}$ (or $K_{\mathrm{b}}$ ) values and the $\mathrm{O} / \mathrm{C}$ atomic ratio determined by XPS was found, showing that the removal of extractives (that have low $\mathrm{O} / \mathrm{C}$ ) exposes the more acidic and basic groups of lignocellulose, thus enhancing the acid-base properties of the material surface.

The effect of preliminary hot water extraction on the surface properties of eucalypt and sugar maple (Acer Saccharum) kraft pulps was also considered: kraft pulps with kappa number of 15 obtained from Acer saccharum and Eucalyptus globulus prepared

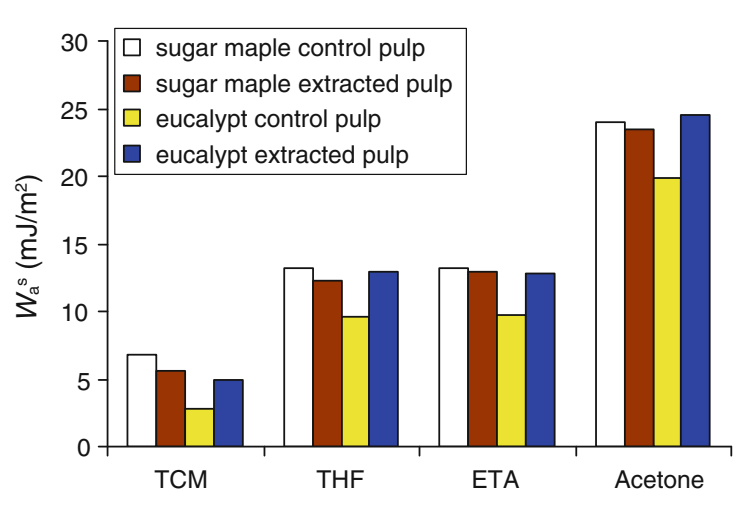

Fig. 2 Works of adhesion of A. saccharum and E. globulus kraft pulps with several polar probes at $40{ }^{\circ} \mathrm{C}$ as determined by IGC (TCM trichloromethane, THF tetrahydrofurane, ETA ethyl acetate) (Gamelas et al. 2013)

with and without hot water extraction (HWE) before cooking were analysed by IGC and XPS (Duarte et al. 2012; Gamelas et al. 2013). It should be noted that HWE is used to extract hemicelluloses from the material (the xylan amount is reduced from about $16 \%$ in the reference pulp to ca. $3 \%$ in the extracted pulp). In the case of $A$. saccharum pulps, the dispersive component of the surface energy at $40{ }^{\circ} \mathrm{C}$ determined by IGC was $39.8 \mathrm{~mJ} \mathrm{~m}^{-2}$ (control pulp without HWE) and $36.7 \mathrm{~mJ} \mathrm{~m}^{-2}$ (HWE pulp). Eucalyptus globulus pulps resulted in $\gamma_{\mathrm{s}}^{\mathrm{d}}$ values of $30.8 \mathrm{~mJ} \mathrm{~m}^{-2}$ (control) and $34.9 \mathrm{~mJ} \mathrm{~m}^{-2}$ (HWE). The higher values of $\gamma_{\mathrm{s}}^{\mathrm{d}}$ for sugar maple pulps were interpreted as resulting from the influence of lower amounts of extractives or lignin at their surfaces, as revealed by XPS. Interestingly, and in line with the $\gamma_{\mathrm{s}}^{\mathrm{d}}$ results, the acid-base character of the sugar maple pulp surface was slightly reduced with previous HWE, whereas, for E. globulus, it was greatly enhanced (Fig. 2). In this context, it should be noted that $\gamma_{\mathrm{s}}^{\mathrm{d}}$ data of $38-39 \mathrm{~mJ} \mathrm{~m}^{-2}$ were reported for 
Table 5 Effect of the beating on the surface properties of bleached pulps

\begin{tabular}{llccc}
\hline Pulps & $\gamma_{\mathrm{s}}^{\mathrm{d}}\left(\mathrm{mJ} \mathrm{m}^{-2}\right)^{\mathrm{a}}$ & $W_{\mathrm{a}}^{\mathrm{s}}(\mathrm{THF}) / W_{\mathrm{a}}^{\mathrm{s}}(\mathrm{TCM})^{\mathrm{a}}$ & $\Delta H_{\mathrm{a}}^{\mathrm{s}}(\mathrm{THF}) / \Delta H_{\mathrm{a}}^{\mathrm{s}}(\mathrm{TCM})^{\mathrm{b}}$ & $K_{\mathrm{a}} / K_{\mathrm{b}}^{\mathrm{b}}$ \\
\hline Bleached eucalypt pulp before beating & 45.0 & 8.7 & 17.5 & 2.0 \\
Bleached eucalypt pulp after beating & 48.2 & 11.4 & 21.6 & 3.1 \\
Bleached softwood pulp before beating & 41.7 & 4.1 & 2.3 & 0.35 \\
Bleached softwood pulp after beating & 44.7 & 4.6 & 3.8 & 0.45 \\
\hline
\end{tabular}

Carvalho et al. (2005a), Gamelas et al. (2011); THF = tetrahydrofurane; TCM = trichloromethane

${ }^{\text {a }}$ Measurements made at $40{ }^{\circ} \mathrm{C}$

${ }^{\mathrm{b}} K_{\mathrm{a}}$ and $K_{\mathrm{b}}$ values have been obtained from the $\Delta H_{\mathrm{a}}^{\mathrm{s}}$ of several probes

red maple (Acer rubrum) wood after extraction at $160{ }^{\circ} \mathrm{C}$ for $90 \mathrm{~min}$, whereas those values of the original wood samples were $36-37 \mathrm{~mJ} \mathrm{~m}^{-2}$ (Mills et al. 2009; Paredes et al. 2009).

The effect of the beating process on the surface energetics of bleached pulp fibers was studied. Firstly, it was claimed that this process did not affect the dispersive component of the surface energy of bleached spruce kraft pulp (Gurnagul and Gray 1987). However, later results on eucalypt kraft pulps (Carvalho et al. 2005a), as well as on softwood pulps (Gamelas et al. 2011), have typically showed an increase of the $\gamma_{\mathrm{s}}^{\mathrm{d}}$ values after beating (Table 5). The acid-base character of the fibers surface was also enhanced after beating with a higher increase of the acidic feature. The increase of the $W_{\mathrm{a}}^{\mathrm{s}}$ (tetrahydrofurane) $/ W_{\mathrm{a}}^{\mathrm{s}}$ (trichloromethane), $-\Delta H_{\mathrm{a}}^{\mathrm{s}}$ (tetrahydrofurane)/ $-\Delta H_{\mathrm{a}}^{\mathrm{s}}$ (trichloromethane) and $K_{\mathrm{a}} / K_{\mathrm{b}}$ ratios after beating (Table 5) indicates that there is a larger number of highest-energy acidic sites relative to that of highestenergy basic sites upon the beating operation. This was interpreted as being due to an increase of the accessibility on the fibers surface of the $\mathrm{OH}$ functional groups (acidic) relatively to that of the oxygen atoms (basic) not bound to hydrogen as a consequence of the beating action (Carvalho et al. 2005a, Gamelas et al. 2011).

It is accepted that the pulp bleaching promotes an increase of the dispersive component of the pulp surface energy. This has been attributed to the removal of components from the pulp surface, with a surface energy lower than cellulose: mainly residual lignin or fragments of lignin (Lundqvist et al. 1995; Boras et al. 1997). The introduction of an oxygen delignification stage prior to bleaching by conventional DEDED sequence (D and $\mathrm{E}$ are chlorine dioxide and alkaline extraction stages, respectively) of eucalypt kraft pulp resulted in a decrease of the $\gamma_{\mathrm{s}}^{\mathrm{d}}$ value (Carvalho et al. 2005b). Interestingly, the Lewis acidic character of the fibers surface was greatly enhanced by the incorporation of the oxygen stage in the bleaching process. The oxygen stage was suggested to cause a stronger oxidation of the fiber surface, increasing the amount of carboxylic groups.

Surface properties of non-woody plant fibers measured by IGC

Recently, some attention has been paid to the study of the surface properties of non-woody fiber types using IGC (Gassan et al. 2000; Gulati and Sain 2006a; Heng et al. 2007; Mills et al. 2008; Cordeiro et al. 2011a, b, 2012; Ramires and Frollini 2012). Non-woody fibers can be classified according to the part of the plant from where they are collected, namely in leaf, bast, fruit, seed, grass and stalk. These naturally occurring materials, similarly to wood fibers, are mainly composed of cellulose, lignin and hemicelluloses (Mills et al. 2008; Cordeiro et al. 2011a). However, the relative amounts of the different components are much different from those of wood fibers and differ widely within the various types of vegetable fibers. A list of the $\gamma_{\mathrm{s}}^{\mathrm{d}}$ values reported for non-woody plant fibers is given in Table 6 . The systematization of the data has shown to be quite difficult due to the several factors involved. In addition, quite different values for the same plant have been reported in different studies (e.g., hemp, flax, and sisal fibers, Table 6). Notwithstanding, it has been proposed by Mills that as the lignin and hemicelluloses content decreases and the cellulose content increases higher values are obtained for $\gamma_{\mathrm{s}}^{\mathrm{d}}$ (Mills et al. 2008). This correlation, however, 
Table 6 Values of the dispersive component of the surface energy $\left(\gamma_{\mathrm{s}}^{\mathrm{d}}, \mathrm{mJ} \mathrm{m}^{-2}\right)$ for non-woody fibers obtained by IGC
${ }^{a}$ From Gulati and Sain (2006a)

b From Heng et al. (2007) $\left(30{ }^{\circ} \mathrm{C}\right)$

c From Gassan et al. (2000) $\left(35^{\circ} \mathrm{C}\right)$

d From Ramires and Frollini (2012) $\left(30{ }^{\circ} \mathrm{C}\right)$
Mills et al. (2008) Cordeiro et al. (2011a) $\left(40{ }^{\circ} \mathrm{C}\right)$ $\left(25^{\circ} \mathrm{C}\right)$

Cordeiro et al. (2011b) $\left(25^{\circ} \mathrm{C}\right)$

Fiber type

Fiber

Grass fibers

Wheat straw

35.4

Wheat pulp bleached

38.5

Rice hulls

Reed

37.2

Bast fibers

Hemp

35.9

$38^{\mathrm{a}}$

$40.7^{\mathrm{b}}$

Flax

34.9

$43.1^{\mathrm{b}}$

Kenaf

36.9

Jute

43.5

$41^{\mathrm{c}}$

Ramie

Abaca

41.2

$49.3^{\mathrm{d}}$

$38.3^{\mathrm{b}}$

Agave

Agave hybrid

Pineapple

Curaua

Pita Mexicana

Piassava

Sorghum

Seed hair fibers

\section{Cotton}

Poplar seed

38.9

Fruit hair fibers

$\begin{array}{lr}\text { Kapok } & 37.7 \\ \text { Coir } & 36.4 \\ \text { Assai } & - \\ \text { Silk floss } & -\end{array}$

39.4

$-$

36.2

38.7

$\begin{array}{ll}- & - \\ - & - \\ - & -\end{array}$

$-$

38.8

44.5

48.3

$-$

46.7

45.5

38.4

41.4

37.7

36.4

$\begin{array}{ll}- & 52.4\end{array}$

$\begin{array}{ll}- & 47.8\end{array}$
46.7

51.4

42.8

37.5

42.0

37.2

39.6

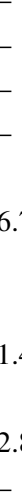

$-$

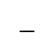

$-$

$-$ was not so obvious for the several vegetable fibers studied by Cordeiro et al. (2011a, b, 2012). As mentioned in "Cellulose analyses by IGC" section of the present review, other parameters such as crystallinity and morphology of the surface (crystallinity is due to cellulose structure since lignin and hemicelluloses are amorphous) can influence the value obtained for $\gamma_{\mathrm{s}}^{\mathrm{d}}$ (Papirer et al. 2000).

In most of the reported studies concerning nonwoody fibers, the authors focused in searching correlations between the $\gamma_{\mathrm{s}}^{\mathrm{d}}$ value, which is a IGC surface parameter, and the chemical composition or 
Table 7 Values of the Lewis acidity $\left(K_{\mathrm{a}}\right)$ and basicity $\left(K_{\mathrm{b}}\right)$ constants and of the $\Delta G_{\mathrm{a}}^{\mathrm{s}}$ (tetrahydrofurane)/ $\Delta G_{\mathrm{a}}^{\mathrm{s}}($ dichloromethane) ratios for non-woody fibers obtained by IGC

\begin{tabular}{|c|c|c|c|c|c|c|c|c|c|c|}
\hline \multirow[t]{2}{*}{ Fiber type } & \multirow[t]{2}{*}{ Fiber } & \multicolumn{3}{|c|}{ Mills et al. (2008) } & \multicolumn{3}{|c|}{ Cordeiro et al. (2011a) } & \multicolumn{3}{|c|}{ Cordeiro et al. (2011b) } \\
\hline & & $K_{\mathrm{a}}$ & $K_{\mathrm{b}}$ & $\Delta G_{\mathrm{a}}^{\mathrm{s} \text { ratio }}$ & $K_{\mathrm{a}}$ & $K_{\mathrm{b}}$ & $\Delta G_{\mathrm{a}}^{\mathrm{s} \text { ratio }}$ & $K_{\mathrm{a}}$ & $K_{\mathrm{b}}$ & $\Delta G_{\mathrm{a}}^{\mathrm{s} \text { ratio }}$ \\
\hline \multirow[t]{4}{*}{ Grass fibers } & Wheat straw & 0.15 & 0.70 & - & & & & & & \\
\hline & Wheat pulp bleached & 0.10 & 0.47 & - & & & & & & \\
\hline & Rice hulls & 0.21 & 0.38 & - & & & & & & \\
\hline & Reed & 0.15 & 0.61 & - & & & & & & \\
\hline \multirow[t]{8}{*}{ Bast fibers } & Hemp & 0.16 & 0.49 & - & & & & 0.11 & 0.27 & 1.1 \\
\hline & & $0.11^{\mathrm{a}}$ & $0.12^{\mathrm{a}}$ & & & & & & & \\
\hline & & $0.05^{\mathrm{b}}$ & $0.24^{\mathrm{b}}$ & & & & & & & \\
\hline & Flax & 0.17 & 0.49 & - & & & & 0.12 & 0.22 & 1.0 \\
\hline & & $0.12^{\mathrm{a}}$ & $0.10^{\mathrm{a}}$ & & & & & & & \\
\hline & Kenaf & 0.07 & 0.32 & - & & & & 0.09 & 0.14 & 1.1 \\
\hline & Jute & 0.01 & 0.00 & - & 0.10 & 0.17 & 1.1 & & & \\
\hline & Ramie & & & & 0.10 & 0.18 & 1.1 & & & \\
\hline \multirow[t]{10}{*}{ Leaf fibers } & Abaca & 0.12 & 0.59 & - & & & & & & \\
\hline & Sisal & 0.38 & 0.74 & - & 0.09 & 0.12 & 1.0 & 0.08 & 0.26 & 1.2 \\
\hline & & $0.11^{\mathrm{a}}$ & $0.07^{\mathrm{a}}$ & & & & & & & \\
\hline & Agave & & & & & & & 0.11 & 0.15 & 1.2 \\
\hline & Agave hybrid & & & & & & & 0.09 & 0.33 & 1.1 \\
\hline & Pineapple & & & & & & & 0.10 & 0.28 & 1.0 \\
\hline & Curaua & & & & 0.11 & 0.14 & 1.0 & & & \\
\hline & Pita Mexicana & & & & 0.09 & 0.36 & 1.1 & & & \\
\hline & Piassava & & & & 0.09 & 0.15 & 1.1 & & & \\
\hline & Sorghum & & & & 0.10 & 0.15 & 1.1 & & & \\
\hline \multirow[t]{2}{*}{ Seed hair fibers } & Cotton & 0.06 & 0.50 & - & & & & & & \\
\hline & Poplar seed & 0.10 & 0.42 & - & & & & & & \\
\hline \multirow[t]{4}{*}{ Fruit hair fibers } & Kapok & 0.14 & 1.05 & - & & & & & & \\
\hline & Coir & 0.19 & 0.20 & - & 0.10 & 0.19 & 1.1 & & & \\
\hline & Assai & & & & 0.10 & 0.31 & 1.1 & & & \\
\hline & Silk floss & & & & 0.11 & 0.27 & 0.9 & & & \\
\hline
\end{tabular}

$K_{\mathrm{a}}$ and $K_{\mathrm{b}}$ values have been obtained from the $\Delta H_{\mathrm{a}}^{\mathrm{s}}$ parameter (Mills et al. 2008; Heng et al. 2007; Gulati and Sain 2006a) or from the $\Delta G_{\mathrm{a}}^{\mathrm{s}}$ parameter at $25^{\circ} \mathrm{C}($ Cordeiro et al. $2011 \mathrm{a}, \mathrm{b}) ; \Delta G_{\mathrm{a}}^{\mathrm{s}}$ ratio refers to $\Delta G_{\mathrm{a}}^{\mathrm{s}}$ (tetrahydrofurane) $/ \Delta G_{\mathrm{a}}^{\mathrm{s}}$ (dichloromethane)

${ }^{a}$ From Heng et al. (2007)

${ }^{\mathrm{b}}$ From Gulati and Sain (2006a)

crystallinity indexes of the materials, which are actually bulk parameters. It is known that IGC is sensitive only to the material surface and, in particular, to the highest-energy sites of the surface. Thus, the correlation with bulk parameters, such as those mentioned, may not be the most correct approach in order to understand the results obtained by this technique. For instance, minor fibrous components, such as extractives, are often present in high concentration at the fiber surface, although they may represent an insignificant amount of the sample bulk. Its presence should have a major influence on the surface properties, including the potential to establish London forces and acid-base interactions. In this context, a special attention could be paid to complementary results provided by XPS. This has been clearly demonstrated in the work of Rjiba et al. (2007) for unextracted and ethanol-extracted cotton fibers. Cotton fibers are composed mostly of $\alpha$-cellulose (88-97 wt\%) and non-cellulosics such as waxes, 
proteins, pectins, inorganics and other substances, with typically less than $2 \mathrm{wt} \%$ of each minor component. However, XPS results showed that the surface of the analysed unextracted cotton fibers was essentially constituted by waxes (very low $\mathrm{O} / \mathrm{C}$ atomic ratio and high $\mathrm{C} 1(\mathrm{C}-\mathrm{H} ; \mathrm{C}-\mathrm{C})$ percentage $)$. After ethanol extraction, both the $\mathrm{O} / \mathrm{C}$ atomic ratio and the oxygen-containing chemical groups (C2 percentage) largely increased but were still low in comparison to the values usually obtained for the surface of cellulosic materials (Belgacem et al. 1995). This study clearly illustrates that for cellulosic materials, the chemical composition of the surface can be indeed much different from that of the bulk. Regarding the IGC data, the $\gamma_{\mathrm{s}}^{\mathrm{d}}$ values (at $30{ }^{\circ} \mathrm{C}$ ) were of about $40 \mathrm{~mJ} \mathrm{~m}^{-2}$ for raw cotton and $30 \mathrm{~mJ} \mathrm{~m}^{-2}$ for the extracted cotton fibers showing that the presence of waxes plays a major role on the surface energy of cotton fibers (Rjiba et al. 2007).

The acid-base parameters, $K_{\mathrm{a}}$ and $K_{\mathrm{b}}$, of the mentioned non-woody fibers have also been obtained. These were calculated from Eq. (18) by taking the $\Delta H_{\mathrm{a}}^{\mathrm{s}}$ parameter obtained from the plot of $\Delta G_{\mathrm{a}}^{\mathrm{s}} / T$ versus $1 / T$ at several temperatures (Gulati and Sain 2006a; Heng et al. 2007; Mills et al. 2008) or by using the $\Delta G_{\mathrm{a}}^{\mathrm{s}}$ parameter obtained at a single temperature (Cordeiro et al. 2011a, b, 2012). The results are summarized in Table 7 . In general, the $K_{\mathrm{b}}$ values have been higher than the $K_{\mathrm{a}}$ ones, suggesting, at first glance, that the surfaces are predominantly basic. In fact, this seems very likely for untreated hemp fibers for which $-\Delta G_{\mathrm{a}}^{\mathrm{s}}$ (trichloromethane) $>-\Delta G_{\mathrm{a}}^{\mathrm{s}}$ (tetrahydrofurane or ethyl ether) (Gulati and Sain 2006a). The authors have attributed this result to the presence of extractives like triglycerides rendering the fiber's surface more basic than acidic. However, the majority of the analysed non-woody fibers showed a $\Delta G_{\mathrm{a}}^{\mathrm{s}}$ (tetrahydrofurane) $/ \Delta G_{\mathrm{a}}^{\mathrm{s}}$ (dichloromethane or trichloromethane) ratio $\geq 1$ (Table 7). Thus, it cannot be concluded, based only on the $K_{\mathrm{a}}$ and $K_{\mathrm{b}}$ values, that the studied non-woody fibers have a predominant basic character as proposed (Cordeiro et al. 2011a, b), as the direct comparison of $K_{\mathrm{a}}$ with $K_{\mathrm{b}}$ is misleading. On the other hand, the amphoteric character of the surfaces is confirmed, since higher $\Delta G_{\mathrm{a}}^{\mathrm{s}}$ values have been obtained for acetonitrile (among other measurements with tetrahydrofurane, dichloromethane, ethyl acetate and acetone), which is an amphoteric probe (Cordeiro et al. 2011a, b).
Flax fibers were submitted to two different treatments, acetylation and stearation, and analysed by IGC. Typically, the acetylation greatly increased the dispersive component of the surface energy while in the case of the stearic acid treatment a reduction in the $\gamma_{\mathrm{s}}^{\mathrm{d}}$ value was found (Zafeiropoulos et al. 2002). The polar characteristics of the fibers surface (evaluated by the measurement of $-\Delta G_{\mathrm{a}}^{\mathrm{s}}$ with acetone, ethanol and ethyl acetate) were also enhanced during acetylation due to the substitution of hydroxyl groups by the more polar ester bonds, while the opposite occurred for the stearic acid treatment. The surface properties of flax fibers after scouring followed by bleaching were also evaluated by IGC (Abdel-Halim 2012). It was found that the $\gamma_{\mathrm{s}}^{\mathrm{d}}$ values follow the order bleached fibers $>$ scoured fibers $>$ raw fibers. This was attributed to the removal of non-cellulosic components (lignin, hemicelluloses, waxes, pectins, proteins) from the fiber surface in the course of the scouring and bleaching treatments, increasing the exposure of the cellulose molecules for interaction with the apolar probes. Experiments were also carried out at different relative humidity values namely 0,30 and $70 \%$. It was found that the dispersive component of the surface energy is almost independent of the humidity content of the fibers. In contrast, the $-\Delta G_{\mathrm{a}}^{\mathrm{s}}$ values with polar probes (ethanol, ethyl acetate, acetone) generally increased by increasing the humidity level (AbdelHalim 2012). Similarly, the bleached cotton wool showed a significantly higher $\gamma_{s}^{d}$ value than the unbleached (Reutenauer and Thielmann 2003). The specific component of the free energy of adsorption of ethanol and ethyl acetate were also significantly higher for the bleached cotton in comparison to the unbleached sample. The authors argued that this could result from an increase in the surface roughness caused by the bleaching process, thus increasing the available sites for interaction (Reutenauer and Thielmann 2003). However, the chemical changes occurring at the fibers surface during bleaching cannot be disregarded.

Megiatto et al. (2007) chemically modified sisal fibers by $\mathrm{ClO}_{2}$ or dichromate oxidation and reaction with furfuryl alcohol (FA) or polyfurfuryl alcohol (PFA) and determined the dispersive component of the surface energy and the acid-base character of the surface. The $\gamma_{\mathrm{s}}^{\mathrm{d}}$ value greatly increased with the modifications from $21 \mathrm{~mJ} \mathrm{~m}^{-2}$ (untreated fibers) up to $63-70 \mathrm{~mJ} \mathrm{~m}^{-2}$ (at $30{ }^{\circ} \mathrm{C}$ ). The acidity of the 
Table 8 Specific interaction parameter $\left(I_{\mathrm{sp}}\right)$ and tensile strength for composites of newsprint fibers with PVC

\begin{tabular}{lll}
\hline Fibers & $I_{\mathrm{sp}}^{\mathrm{a}}$ & $\begin{array}{l}\text { Tensile strength } \\
(\mathrm{MPa})\end{array}$ \\
\hline $\begin{array}{l}\text { Untreated newsprint fibers } \\
\begin{array}{l}\text { Maleated polypropylene-treated } \\
\text { fibers }\end{array}\end{array}$ & 0.70 & $28.5 \pm 0.8$ \\
$\begin{array}{l}\text { Dichlorodiethylsilane-treated fibers } \\
\text { Aminosilane-treated fibers }\end{array}$ & 0.72 & $30.0 \pm 1.9$ \\
Phthalic anhydride-treated fibers & 0.85 & $38.3 \pm 3.1$ \\
& 0.72 & $29.4 \pm 0.8$
\end{tabular}

Matuana et al. (1998)

${ }^{\text {a }}$ Calculated following Eq. (20)

surface as measured by the value of $-\Delta G_{\mathrm{a}}^{\mathrm{s}}$ of tetrahydrofurane (donor probe) decreased with the modifications. Besides, in all cases the $-\Delta G_{\mathrm{a}}^{\mathrm{s}}$ of tetrahydrofurane was higher than the $-\Delta G_{\mathrm{a}}^{\mathrm{s}}$ of trichloromethane (acceptor probe), showing that both the untreated and the treated fibers had a more acidic than basic character. Overall, the grafting of PFA and FA chains on the sisal fiber surface resulted in a decrease of the more accessible $\mathrm{OH}$ polar groups from the cellulose and lignin structures and in the introduction of non-polar moieties which could contribute to the increase of $\gamma_{\mathrm{s}}^{\mathrm{d}}$ and to the diminishing of the acidic character of the fiber surface. The $\gamma_{\mathrm{s}}^{\mathrm{d}}$ value also significantly increased after the modification of sisal fibers with methylolated lignins (Megiatto et al. 2008). In addition, with the modification there was a decrease in both the $-\Delta G_{\mathrm{a}}^{\mathrm{s}}$ (tetrahydrofurane) and $-\Delta G_{\mathrm{a}}^{\mathrm{s}}$ (trichloromethane) values, but more pronounced with tetrahydrofurane. These results were attributed to the grafting of lignins to the surface of sisal fibers.

Compatibility of cellulose-based materials with polymeric matrices to produce composites

The compatibility of unmodified/modified cellulose fibers and lignocellulosic fibers with polystyrene matrix was considered (Felix et al. 1993; Simonsen et al. 1997; Rials and Simonsen 2000; Tze et al. 2006a, b). Based on the calculation of IGC matrix-filler Lewis acid-base interaction parameter (following Eq. 19) between fibers and polystyrene, it was predicted that aminopropyl-silanated cellulose (lyocell) fibers have higher potential than the unmodified
Table 9 Specific interaction parameter $\left(I_{\mathrm{sp}}\right)$ and tensile strength for composites of hemp nanofibers with polyhydroxybutyrate

\begin{tabular}{|c|c|c|c|}
\hline & $I_{\mathrm{sp}}^{\mathrm{a}}$ & $\begin{array}{l}\text { Tensile } \\
\text { strength } \\
(\mathrm{MPa})\end{array}$ & $\begin{array}{l}\text { E-modulus } \\
(\mathrm{GPa})\end{array}$ \\
\hline $\begin{array}{l}\text { Untreated hemp } \\
\text { nanofibers }\end{array}$ & 0.20 & 17.7 & 1.55 \\
\hline $\begin{array}{l}\text { Styrene maleic anhydride- } \\
\text { coated hemp nanofibers }\end{array}$ & 0.41 & 20.7 & 1.93 \\
\hline Polyhydroxybutyrate $^{\mathrm{b}}$ & - & 15.3 & 1.41 \\
\hline
\end{tabular}

Wang and Sain (2007); composites contained 5 wt $\%$ loading of nanofibers

a Calculated following Eq. (19)

b Results of polyhydroxybutyrate, solely, are given for comparison

or the phenylaminopropyl-, phenyl- or octadecylsilanated fibers for bonding with polystyrene in a composite system (Tze et al. 2006a, b). This was confirmed from measurements of the maximum interfacial shear stress in the resultant composites.

The compatibility of untreated/treated newsprint fibers with PVC matrix was also examined (Matuana et al. 1998). Newsprint fibers treated with $\gamma$-aminopropyltriethoxysilane showed higher $I_{\mathrm{sp}}$ values with PVC than those treated with dichlorodiethylsilane, maleated polypropylene or phthalic anhydride (Table 8 ). The prediction of a better compatibility between the aminosilane-treated fibers and PVC, based on the calculation of the $I_{\mathrm{sp}}$ values, was confirmed by the measurement of a higher tensile strength in the composite with the aminosilane-treated fibers (Table 8). The compatibility of PVC and PVCb-PHPA-b-PVC (PHPA = poly(hydroxypropyl acrylate)) block copolymers with pine wood flour has been studied based on the calculation of $I_{\mathrm{sp}}$ parameter (following Eq. 20) for composites with $40 \mathrm{wt} \%$ of pine wood flour and PVC, or different block copolymers, as the matrix of the composite (Rocha et al. 2009). The results showed that the chemical adhesion between the wood flour filler and the polymeric matrix should increase when using the copolymer instead of PVC. Among the considered matrices, the copolymer with the higher molecular weight was proposed to give the greater degree of adhesion to wood flour.

The surface of wood flour was modified by benzylation and composites of the neat and the treated 
wood flours with polypropylene block copolymer (PP) were produced. The authors found an interesting direct correlation between the dispersive component of the surface energy of the wood flour samples and the tensile strength of the PP/wood composites containing $20 \mathrm{wt} \%$ of filler (Dominkovics et al. 2007). The very close linear correlation confirms the relationship of adhesion and strength. On the other hand, Chtourou and co-authors (Chtourou et al. 1997) have found linear correlations between the values of the specific interaction parameter (calculated using Eq. 20) and the strength properties (breaking length, burst index and tear index) of composite sheets made of explosion pulp/kraft pulp from hardwood and pre-treated polyethylene. In this way, they have proposed that IGC could be a useful technique for evaluating surface treatment in order to maximize inter-fiber adhesion.

Hemp nanofibers were modified by several chemical treatments and their compatibility with poly(lactic acid) (PLA) and polyhydroxybutyrate (PHB) estimated based on IGC measurements (Eq. 19). The IGC results indicated that styrene maleic anhydride coated and ethylene acrylic acid coated hemp nanofibers had higher potential to interact with PLA or PHB than the untreated fibers (Wang and Sain 2007). This was confirmed by measurements of the mechanical properties of the composites incorporating the styrene maleic anhydride-coated hemp nanofibers (Table 9).

Interestingly, hemp fibers treated with Ophiostoma ulmi (a fungus obtained from elm tree infected with Dutch elm disease) showed better acid-base compatibility (Eq. 19) with an unsaturated polyester resin than the untreated fibers. In agreement with the IGC supposition, composites prepared using the treated fibers (12 wt \%) and the polyester showed improved flexural strength and flexural modulus, which measure the strength of the composite (Gulati and Sain 2006b). The relatively larger acid-base interactions between the treated fibers and the resin must have improved the interfacial adhesion in the composite.

Recently, it was proposed that for the same type of filler the mechanical properties of the composites increased when the ratio of the work of adhesion (matrix-filler) to the work of cohesion (matrix-matrix or filler-filler) increased (Oporto et al. 2011). However, a careful reading of this article shows that this trend was valid only in a small number of cases. The Lewis acid-base matrix-filler interaction parameter $\left(I_{\text {sp }}\right)$, determined using Eqs. (19) or (20), is probably more appropriate to predict the compatibility between components in composite structures.

\section{Conclusions}

Inverse gas chromatography (IGC), at infinite dilution conditions, is an appropriate tool to study the physicochemical surface properties of cellulose and lignocellulosic materials, overcoming the problems typically found in the surface analyses of the latter materials by methods based on contact angle measurements (e.g., surface roughness, the presence of pores, surface energy gradients, etc.). Relevant information including the dispersive component of the surface free energy, thermodynamic data on the adsorption of polar and apolar probes, acid-base character of the material surface, and matrix-filler specific acid-base interaction parameters, can be accessed by this technique.

The theoretical background of inverse gas chromatography is well established. However, due to the several approaches available within IGC, care must be taken when interpreting the obtained results. In particular, the acid-base constants, $K_{\mathrm{a}}$ and $K_{\mathrm{b}}$, depend largely on the type of physical probes used for their determination and on the employed calculation method (i.e., based on $\Delta H_{\mathrm{a}}^{\mathrm{s}}$ parameter, obtained from the plot of $\Delta G_{\mathrm{a}}^{\mathrm{s}} / T$ versus $1 / T$ at several temperatures, or from $\Delta G_{\mathrm{a}}^{\mathrm{s}}$, obtained at a single temperature). On the other hand, regarding the calculation of the dispersive component of the surface energy $\left(\gamma_{\mathrm{s}}^{\mathrm{d}}\right)$, the most employed methods (Schultz/Lavielle and Dorris/ Gray) typically afford comparable results at a given temperature. Anyway, it must be stressed that only the highest-energy sites of the surface are measured by IGC. Finally, it is recommended the concomitant use of other surface sensitive methods, such as XPS, in order to corroborate the IGC results and get a better understanding of the surface physicochemical properties of the materials under analysis.

The use of IGC as a tool to predict the compatibility of functionalized cellulosic fibrous materials with polymers for the production of composites deserves a special attention. From the standpoint of the optimisation of the performance properties of solid composite mixtures, specific interaction numbers can give important leads with respect to optimising the adhesion in a range of compositions. 
Acknowledgments The author thanks Gabriela Martins for her helpful suggestions to this paper.

\section{References}

Abdel-Halim ES (2012) Physiochemical properties of differently pretreated cellulosic fibers. Carbohydr Polym 88:1201-1207

Bach S, Belgacem MN, Gandini A (2005) Hydrophobisation and densification of wood by different chemical treatments. Holzforschung 59:389-396

Belgacem MN (2000) Characterization of polysaccharides, lignin and other woody components by inverse gas chromatography: a review. Cellul Chem Technol 34:357-383

Belgacem MN, Gandini A (1999) IGC as a tool to characterize dispersive and acid-base properties of the surface of fibers and powders. In: Pfefferkorn E (ed) Interfacial phenomena in chromatography. Marcel Dekker, New York, pp 41-124

Belgacem MN, Czeremuszkin G, Sapieha S, Gandini A (1995) Surface characterization of cellulose fibres by XPS and inverse gas chromatography. Cellulose 2:145-157

Belgacem MN, Blayo A, Gandini A (1996) Surface characterization of polysaccharides, lignins, printing ink pigments, and ink fillers by inverse gas chromatography. J Colloid Interface Sci 182:431-436

Boras L, Sjostrom J, Gatenholm P (1997) Characterization of surfaces of CTMP fibers using inverse gas chromatography combined with multivariate data analysis. Nord Pulp Paper Res J 12(4):220-224

Borges JP, Godinho MH, Belgacem MN, Martins AF (2001) New bio-composites based on short fibre reinforced hydroxypropylcellulose films. Compos Interface 8:233-241

Botaro VR, Gandini A (1998) Chemical modification of the surface of cellulosic fibres. 2. Introduction of alkenyl moieties via condensation reactions involving isocyanate functions. Cellulose 5:65-78

Brendlé E, Papirer E (1997a) A new topological index for molecular probes used in inverse gas chromatography for the surface nanorugosity evaluation 1 . Method of evaluation. J Colloid Interface Sci 194:207-216

Brendlé E, Papirer E (1997b) A new topological index for molecular probes used in inverse gas chromatography 2 . Application for the evaluation of the solid surface specific interaction potential. J Colloid Interface Sci 194:217-224

Carvalho MG, Santos JMRCA, Martins AA, Figueiredo MM (2005a) The effects of beating, web forming and sizing on the surface energy of Eucalyptus globulus kraft fibres evaluated by inverse gas chromatography. Cellulose 12:371-383

Carvalho MG, Ferreira PJ, Santos JMRCA, Amaral JL, Figueiredo MM (2005b) Effect of extended cooking and oxygen prebleaching on the surface energy of Eucalyptus globulus kraft pulps. J Pulp Paper Sci 31(2):90-94

Chehimi MM, Abel M, Perruchot C, Delamar M, Lascelles SF, Armes SP (1999) The determination of the surface energy of conducting polymers by inverse gas chromatography at infinite dilution. Synth Met 104:51-59

Chen J, Yan N (2012) Hydrophobization of bleached softwood kraft fibers via adsorption of organo-nanoclay. Bioresources 7:4132-4149
Chtourou H, Riedl B, Kokta BV (1995) Surface characterizations of modified polyethylene pulp and wood pulps fibres using XPS and inverse gas chromatography. J Adhes Sci Technol 9:551-574

Chtourou H, Riedl B, Kokta BV (1997) Strength properties of wood-PE composites: influence of pulp ratio and pretreatment of PE fibers. Tappi J 80:141-151

Conder JR, Young CL (1979) Physicochemical measurement by gas chromatography. Wiley-Interscience, New York

Cordeiro N, Gouveia C, Jacob John M (2011a) Investigation of surface properties of physico-chemically modified natural fibres using inverse gas chromatography. Ind Crop Prod 33:108-115

Cordeiro N, Gouveia C, Moraes AGO, Amico SC (2011b) Natural fibers characterization by inverse gas chromatography. Carbohydr Polym 84:110-117

Cordeiro N, Ornelas M, Ashori A, Sheshmani S, Norouzi H (2012) Investigation on the surface properties of chemically modified natural fibres using inverse gas chromatography. Carbohydr Polym 87:2367-2375

Coupas AC, Gauthier H, Gauthier R (1998) Inverse gas chromatography as a tool to characterize ligno-cellulosic fibers modified for composite applications. Polym Compos 19:280-286

Dominkovics Z, Dányádi L, Pukánszky B (2007) Surface modification of wood flour and its effect on the properties of PP/wood composites. Compos Part A Appl Sci 38:1893-1901

Donnet JB, Park SJ, Balard H (1991) Evaluation of specific interactions of solid surfaces by inverse gas chromatography-a new approach based on polarizability of the probes. Chromatographia 31:434-440

Donnet JB, Qin RY, Wang MJ (1992) A new approach for estimating the molecular areas of linear hydrocarbons and their derivatives. J Colloid Interface Sci 153:572-577

Dorris GM, Gray DG (1980) Adsorption of $n$-alkanes at zero surface coverage on cellulose paper and wood fibres. J Colloid Interface Sci 77:353-362

Duarte GV, Gamelas JAF, Ramarao BV, Amidon TE, Ferreira PJ (2012) Properties of extracted Eucalyptus globulus kraft pulps. Tappi J 11(4):47-55

Felix JM, Gatenholm P (1993a) Characterization of cellulose fibers using inverse gas chromatography. Nord Pulp Paper Res J 8(1):200-203

Felix JM, Gatenholm P (1993b) Formation of entanglements at brushlike interfaces in cellulose-polymer composites. J Appl Polym Sci 50:699-708

Felix JM, Gatenholm P, Schreiber HP (1993) Controlled interactions in cellulose-polymer composites. 1. Effect on mechanical properties. Polym Compos 14:449-457

Felix J, Gatenholm P, Schreiber HP (1994) Plasma modification of cellulose fibers: effects on some polymer composite properties. J Appl Polym Sci 51:285-295

Fowkes FM (1964) Attractive forces at interfaces. Ind Eng Chem 56:40

Gadhe JB, Gupta RB, Elder T (2006) Surface modification of lignocellulosic fibers using high-frequency ultrasound. Cellulose 13:9-22

Gamelas JAF, Santos JMRCA, Ferreira PJ (2011) Surface energetics of softwood kraft pulps by inverse gas chromatography. In: Ander P, Bauer W, Heinemann S, Kallio P, 
Passas R, Treimanis A (eds) Fine structure of papermaking fibres. COST Office, Brussels, pp 39-49

Gamelas JAF, Evtyugina MG, Portugal I, Evtuguin DV (2012) New polyoxometalate-functionalized cellulosic fibre/silica hybrids for environmental applications. RSC Adv 2:831-839

Gamelas JAF, Duarte GV, Ferreira PJ (2013) Inverse gas chromatography and XPS of extracted kraft pulps. Holzforschung 67:273-276

Gardner DJ, Oporto GS, Mills R, Samir MASA (2008) Adhesion and surface issues in cellulose and nanocellulose. J Adhesion Sci Technol 22:545-567

Garnier G, Glasser WG (1994) Measurement of the surface free energy of amorphous cellulose by alkane adsorption: a critical evaluation of inverse gas chromatography (IGC). J Adhesion 46:165-180

Garnier G, Glasser WG (1996) Measuring the surface energies of spherical cellulose beads by inverse gas chromatography. Polym Eng Sci 36:885-894

Gassan J, Gutowski VS, Bledzki AK (2000) About the surface characteristics of natural fibres. Macromol Mater Eng 283:132-139

Gauthier R, Joly C, Coupas AC, Gauthier H, Escoubes M (1998a) Interfaces in polyolefin/cellulosic fiber composites: chemical coupling, morphology, correlation with adhesion and aging in moisture. Polym Compos 19:287-300

Gauthier H, Coupas A, Villemagne P, Gauthier R (1998b) Physicochemical modifications of partially esterified cellulose evidenced by inverse gas chromatography. J Appl Polym Sci 69:2195-2203

Goss KU (1997) Considerations about the adsorption of organic molecules from the gas phase to surfaces: implications for inverse gas chromatography and the prediction of adsorption coefficients. J Colloid Interface Sci 190:241-249

Gregorova A, Wimmer R, Hrabalova M, Koller M, Ters T, Mundigler N (2009) Effect of surface modification of beech wood flour on mechanical and thermal properties of poly(3-hydroxybutyrate)/wood flour composites. Holzforschung 63:565-570

Gulati D, Sain M (2006a) Surface characteristics of untreated and modified hemp fibers. Polym Eng Sci 46:269-273

Gulati D, Sain M (2006b) Fungal-modification of natural fibers: a novel method of treating natural fibers for composite reinforcement. J Polym Environ 14:347-352

Gurnagul N, Gray DG (1987) Surface-adsorption at low coverage of normal-alkanes on bleached kraft papers using gas-chromatography. Can J Chem 65:1935-1939

Gutmann V (1978) The donor-acceptor approach to molecular interactions. Plenum Press, New York

Heng JYY, Pearse DF, Thielmann F, Lampke T, Bismarck A (2007) Methods to determine surface energies of natural fibres: a review. Compos Interface 14:581-604

Jacob PN, Berg JC (1994) Acid-base surface energy characterization of microcrystalline cellulose and two wood pulp fiber types using inverse gas chromatography. Langmuir 10:3086-3093

Jandura P, Riedl B, Kokta BV (2002) Inverse gas chromatography study on partially esterified paper fiber. J Chromatogr 969:301-311
Kamdem DP, Riedl B (1991) Characterization of wood fibers modified by phenol-formaldehyde. Colloid Polym Sci 269:595-603

Kamdem DP, Riedl B (1992) Inverse gas chromatography of lignocellulosic fibers coated with a thermosetting polymer: use of peak maximum and conder and young methods. J Colloid Interface Sci 150:507-516

Kamdem DP, Bose SK, Luner P (1993) Inverse gas chromatography characterization of birch wood meal. Langmuir 9:3039-3044

Kazayawoko M, Balatinecz J, Romansky M (1997) Thermodynamics of adsorption of $n$-alkanes on maleated wood fibers by inverse gas chromatography. J Colloid Interface Sci 190:408-415

Kazayawoko M, Balatinecz JJ, Matuana LM (1999) Surface modification and adhesion mechanisms in wood fiberpolypropylene composites. J Mater Sci 34:6189-6199

Kiselev AV (1967) Adsorbents in gas chromatography. In: Giddings JC, Keller RA (eds) Advances in chromatography. Marcel Dekker Co., New York, vol. 4, pp 113-196

Lee HL, Luner P (1989) Characterization of AKD sized papers by inverse gas chromatography. Nord Pulp Paper Res J 4(2):164-172

Lee HL, Luner P (1993) Analysis of the adsorption of alkanes on high surface area cellulose by inverse gas chromatography. J Wood Chem Technol 13:127-144

Liu FP, Rials TG, Simonsen J (1998) Relantionship of wood surface energy to surface composition. Langmuir 14:536-541

Lundqvist A, Odberg L, Berg JC (1995) Surface characterization of non-chlorine-bleached pulp fibers and calciumcarbonate coatings using inverse gas-chromatography. Tappi J 78:139-142

Matuana LM, Woodhams RT, Balatinecz JJ, Park CB (1998) Influence of interfacial interactions on the properties of PVC/cellulosic fiber composites. Polym Compos 19:446455

Matuana LM, Balatinecz JJ, Park CB, Woodhams RT (1999) Surface characteristics of chemically modified newsprint fibers determined by inverse gas chromatography. Wood Fiber Sci 31:116-127

Megiatto JD, Oliveira FB, Rosa DS, Gardrat C, Castellan A, Frollini E (2007) Renewable resources as reinforcement of polymeric matrices: composites based on phenolic thermosets and chemically modified sisal fibers. Macromol Biosci 7:1121-1131

Megiatto JD, Silva CG, Rosa DS, Frollini E (2008) Sisal chemically modified with lignins: correlation between fibers and phenolic composites properties. Polym Degrad Stab 93:1109-1121

Mills RH, Gardner DJ, Wimmer R (2008) Inverse gas chromatography for determining the dispersive surface free energy and acid-base interactions of sheet molding compound-Part II 14 lignocellulosic fiber types for possible composite reinforcement. J Appl Polym Sci 110: 3880-3888

Mills RH, Jara R, Gardner DJ, van Heiningen A (2009) Inverse gas chromatography for determining the surface free energy and acid-base chemical characteristics of a water extracted hardwood (Acer rubrum). J Wood Chem Technol 29(1):11-23 
Mukhopadhyay P, Schreiber HP (1995) Aspects of acid-base interactions and use of inverse gas chromatography. Colloid Surf A 100:47-71

Oporto GS, Gardner DJ, Kiziltas A, Neivandt DJ (2011) Understanding the affinity between components of woodplastic composites from a surface energy perspective. J Adhes Sci Technol 25:1785-1801

Papirer E, Brendle E, Balard H, Vergelati C (2000) Inverse gas chromatography investigation of the surface properties of cellulose. J Adhes Sci Technol 14:321-337

Paredes JJ, Mills R, Howel C, Shaler SM, Gardner DJ, van Heiningen A (2009) Surface characterization of red maple strands after hot water extraction. Wood Fiber Sci 41(1):38-50

Peng S, Zou Q (2007) An investigation on the surface properties of lyocell-based carbon fiber with inverse gas chromatography. J Mater Sci 42:6907-6912

Peterlin S, Planinsek O, Moutinho I, Ferreira P, Dolenc D (2010) Inverse gas chromatography analysis of spruce fibers with different lignin content. Cellulose 17:1095-1102

Pommet M, Juntaro J, Heng JYY, Mantalaris A, Lee AF, Wilson K, Kalinka G, Shaffer MSP, Bismarck A (2008) Surface modification of natural fibers using bacteria: depositing bacterial cellulose onto natural fibers to create hierarchical fiber reinforced nanocomposites. Biomacromolecules 9:1643-1651

Ramires EC, Frollini E (2012) Tannin-phenolic resins: synthesis, characterization, and application as matrix in biobased composites reinforced with sisal fibers. Compos Part B Eng 43:2851-2860

Rani PR, Ramanaiah S, Reddy KS (2011) Lewis acid-base properties of cellulose acetate butyrate by inverse gas chromatography. Surf Interface Anal 43:683-688

Reutenauer S, Thielmann F (2003) The characterization of cotton fibers and the interaction with perfume molecules by inverse gas chromatography (IGC). J Mater Sci 38:2205-2208

Rials TG, Simonsen J (2000) Investigating interphase development in wood polymer composites by inverse gas chromatography. Compos Interface 7:81-92

Riddle FL, Fowkes FM (1990) Spectral shifts in acid-base chemistry. 1. Van der Waals contributions to acceptor numbers. J Am Chem Soc 112:3259-3264

Riedl B, Kamdem DP (1992) Estimation of the dispersive component of surface energy of polymer grafted lignocellulosic fibers with inverse gas chromatography. J Adhes Sci Technol 6:1053-1067

Rjiba N, Nardin M, Dréan J, Frydrych R (2007) A study of the surface properties of cotton fibers by inverse gas chromatography. J Colloid Interface Sci 314:373-380

Rocha N, Gamelas JAF, Gonçalves PM, Gil MH, Guthrie JT (2009) Influence of physical-chemical interactions on the thermal stability and surface properties of poly(vinyl chloride)-b-poly(hydroxypropyl acrylate)-b-poly(vinyl chloride) block copolymers. Eur Polym J 45:3389-3398

Saint Flour C, Papirer E (1982) Gas solid chromatography: a method of measuring surface free energy characteristics of short glass fibers. 2. Through retention volumes measured near zero surface coverage. Ind Eng Chem Prod Res Dev 21:666-669
Saint Flour C, Papirer E (1983) Gas-solid chromatography: a quick method of estimating surface free energy variations induced by the treatment of short glass fibers. J Colloid Interface Sci 91:69-75

Santos JMRCA, Guthrie JT (2005) Analysis of interactions in multicomponent polymeric systems: the key-role of inverse gas chromatography. Mat Sci Eng R 50:79-107

Sasa B, Odon P, Stane S, Julijana K (2006) Analysis of surface properties of cellulose ethers and drug release from their matrix tablets. Eur J Pharm Sci 27:375-383

Schultz J, Lavielle L (1989) Interfacial properties of carbonfiber epoxy matrix composites. In: Lloyd DR, Ward TC, Schreiber HP (eds) Inverse gas chromatography characterization of polymers and other materials, ACS symposium series, 391. American Chemical Society, Washington, pp 185-202

Schultz J, Lavielle L, Martin C (1987) The role of the interface in carbon fibre-epoxy composites. J Adhesion 23:45-60

Shen Q (2009) Surface properties of cellulose and cellulose derivatives: a review. In: Roman M (ed) Model cellulosic surfaces, ACS symposium series, 1019. American Chemical Society, Washington, pp 259-289

Shen W, Parker IH (1999) Surface composition and surface energetics of various eucalypt pulps. Cellulose 6:41-55

Shen W, Yao W, Li M, Parker I (1998a) Characterization of eucalypt fibre surface using inverse gas chromatography and X-ray photoelectron spectroscopy. Appita J 51(2): 147-151

Shen W, Parker IH, Sheng YJ (1998b) The effects of surface extractives and lignin on the surface energy of eucalypt kraft pulp fibers. J Adhes Sci Technol 12:161-174

Shen W, Sheng YJ, Parker IH (1999) Comparison of the surface energetics data of eucalypt fibers and some polymers obtained by contact angle and inverse gas chromatography methods. J Adhes Sci Technol 13:887-901

Shen W, Filonanko Y, Truong Y, Parker IH, Brack N, Pigram P, Liesegang J (2000) Contact angle measurement and surface energetics of sized and unsized paper. Colloid Surf A 173:117-126

Siddiqui N, Mills RH, Gardner DJ, Bousfield D (2011) Production and characterization of cellulose nanofibers from wood pulp. J Adhes Sci Technol 25:709-721

Simonsen J, Hong Z, Rials TG (1997) The properties of the wood-polystyrene interphase determined by inverse gas chromatography. Wood Fiber Sci 29:75-84

Smidsrod O, Guillet JE (1969) Study of polymer-solute interactions by gas chromatography. Macromolecules 2:272277

Steele DF, Moreton RC, Staniforth JN, Young PM, Tobyn MJ, Edge S (2008) Surface energy of microcrystalline cellulose determined by capillary intrusion and inverse gas chromatography. AAPS J 10:494-503

Tonoli GHD, Almeida AEFD, Pereira-da-Silva MA, Bassa A, Oyakawa D, Savastano H (2010) Surface properties of eucalyptus pulp fibres as reinforcement of cement-based composites. Holzforschung 64:595-601

Trejo-O'Reilly JA, Cavaille JY, Belgacem MN, Gandini A (1998) Surface energy and wettability of modified cellulosic fibres for use in composite materials. J Adhesion 67:359-374 
Tshabalala MA (1997) Determination of the acid-base characteristics of lignocellulosic surfaces by inverse gas chromatography. J Appl Polym Sci 65:1013-1020

Tze WT, Gardner DJ (2001) Contact angle and IGC measurements for probing surface-chemical changes in the recycling of wood pulp fibers. J Adhes Sci Technol 15:223-241

Tze WTY, Gardner DJ, Tripp CP, O’Neill SC (2006a) Cellulose fiber/polymer adhesion: effects of fiber/matrix interfacial chemistry on the micromechanics of the interphase. J Adhes Sci Technol 20:1649-1668

Tze WTY, Walinder MEP, Gardner DJ (2006b) Inverse gas chromatography for studying interaction of materials used for cellulose fiber/polymer composites. J Adhes Sci Technol 20:743-759
Walinder MEP, Gardner DJ (2000) Surface energy of extracted and non-extracted Norway spruce wood particles studied by inverse gas chromatography (IGC). Wood Fiber Sci 32:478-488

Walinder MEP, Gardner DJ (2002) Acid-base characterization of wood and selected thermoplastics. J Adhes Sci Technol 16:1625-1649

Wang B, Sain M (2007) The effect of chemically coated nanofiber reinforcement on biopolymer based nanocomposites. Bioresources 2:371-388

Zafeiropoulos NE, Williams DR, Baillie CA, Matthews FL (2002) Engineering and characterisation of the interface in flax fibre/polypropylene composite materials. Part I. Development and investigation of surface treatments. Compos Part A Appl Sci 33:1083-1093 